\title{
COMMUNICATING SOURCE SEPARATION OF URINE
}

\author{
Stefanie Hörnlein *, Simon Mehling and Jörg Londong
}

Department of Urban Water Management and Sanitation, Bauhaus-Institute for Infrastructure Solutions (b.is), Goetheplatz 7/8, 99423 Weimar, Germany

Article Info:

Received:

31 July 2020

Revised:

11 January 2021

Accepted:

19 January 2021

Available online:

31 March 2021

Keywords:

Sustainable sanitation

Nutrient recovery

Awareness-raising campaign

Urine diversion

\begin{abstract}
One of the main issues regarding the implementation of source-separation-based sanitation systems is user acceptance, which is related directly to the state of knowledge of citizens. A communication platform for the exhibition and interactive information on the topic of resource-oriented sanitation (ROS) was developed as part of the P-BANK transdisciplinary project. The P-BANK platform is based on a toilet in the public space. The communication concept focusses on the actual use of the toilets and the surrounding nutrient cycle. The central object of the communication at the P-BANK, as its name suggests, is the macronutrient phosphorus. This simplification creates a symbolic effect which is supported by the ambiguity of the sound of the chemical symbol " $P$ " for phosphorus in connection with urinating (to pee). Furthermore, this reduction aims at shortening the messages and simplifying the information transfer. In the first project phase, the transportable system was field-tested and evaluated in the context of the 100th anniversary of the Bauhaus in Weimar. After positive reviews and experiences concerning the performance of the technical facilities and the success of the communication concept, the P-BANK will be tested and evaluated in further awareness-raising campaigns.
\end{abstract}

\section{INTRODUCTION}

In addition to water supply and solar energy, macronutrients in the soil are of outstanding importance for flora. Along with nitrogen and potassium, phosphorus is one of the main nutritional elements that is essential for plant health and development. All three macronutrients represent a global challenge in many ways, both now and in the future. This is reflected in the extraction of the nutrients as resources as well as in its role as potential contaminants in urban water management (Schaum, 2018).

\subsection{The role of nutrients}

Modern agriculture is covering the lack of macronutrients (nitrogen, phosphorus, and potassium) and micronutrients by synthetic fertilisers. These fertilisers are produced on the basis of geological resources, e.g. the use of fossil fuels in the production of nitrogen in the Haber-Bosch process and the extraction of phosphate and potassium from mines. Potassium and phosphorus are mined in only a few countries in the world, which leads to geopolitical tensions and may be exacerbated in the future on the basis of the in part already insufficient nutrient supply of the soil (Ciceri et al., 2015; Cordell et al., 2009; Manning, 2015; Manning, 2018). Studies show that a high rate of soils both in developing regions like India as well as developed countries like the UK are deficient in at least one micronutrient (Jones et al., 2013). Alternative sources of phosphorus, nitrogen, and potassium same as micronutrients are essential to maintain food security but also to prevent the increase of considerable geopolitical stress (EcoSanRes, 2005; Razon, 2018; Steen, 1998).

The nutrients important for the soil (especially phosphorus and nitrogen) have a negative impact on the biodiversity of water bodies. The main cause is the massive human impact on the global $\mathrm{P}$ and $\mathrm{N}$ cycles (Rockström et al. 2009) because human excreta that are returned to the natural cycle in the wrong place and in a concentrated form can, for example, lead to eutrophication of waters (Schaum, 2018). Requirements for the elimination of these nutrients contained in human excreta and greywater are already manifested in legislation (Council Directive 91/271/ EEC, 1991).

\subsection{The fate of nutrients in human excreta}

Properly treated faecal material flows are non-problematic substances but valuable resources. Agriculture and food production are connected inevitably to human excreta management (Harder et al., 2020). Of the phosphorus used in Europe, $30 \%$ is lost from human excreta into water bodies or sewage sludge (Schaum, 2018). This is where Resource-Oriented Sanitation Systems (ROS) 
can come into play. As an alternative to the conventional central water-borne sewage system, the core objective of these technical solutions is the recovery of valuable substances from urine, faeces, and greywater. The nutrients are contained primarily in urine and faeces. In conventional sanitation systems, approximately $30 \%$ of the daily drinking water amount per inhabitant (Shouler et al., 1998) is contaminated with nutrients and trace substances, such as pathogenic germs, hormones, heavy metals, and pharmaceuticals, transporting them over long distances to central sewage treatment plants. While the above-mentioned micropollutants pass through mechanical-biological wastewater treatment plants (Ebert, 2013), nutrients are removed from the wastewater without recovery. In principle, nutrient recovery in wastewater treatment plants is possible but related to a high additional procedural expenditure. Regarding this and the mentioned dilution and discharge of nutrient-rich excreta, the adequacy of the central approach is questionable. The approach of ROS is the separation of urine, faeces and greywater at source followed by a targeted treatment and focused reuse of the contained resources. In consequence nutrient cycles can be closed more easily. A separate collection requires modified technical installation facilities, with numerous daily user interactions (Kraus et al., 2019, Larsen et al., 2013; Lienert and Larsen, 2006).

\subsection{Challenges in the implementation of Resource- Oriented Sanitation}

New types of sanitation systems have been the subject of technical research and development in urban water management for several years. These technologies can be considered technologically mature on the basis of various fact sheets and worksheets. Nevertheless, these concepts so far have been implemented exclusively within the framework of pilot projects and research projects and are not of much concern to society at large (Larsen et al., 2013, Blanken et al., 2019, Schramm et al., 2018).

The reasons for this are diverse and are based largely on the status quo of the water management infrastructure and existing laws. For example, one of the main reasons for rejecting the implementation of ROS is the constructional expenditure for material flow separation in existing buildings, which is associated with extensive investments. Another issue is the limited approval of fertilisers produced from human excreta. Of particular relevance is the acceptance by society, some of which, according to various focus group studies (e.g. Lienert and Larsen, 2006, Pahl-Wostl et al., 2003), are in favour of the use of ROS in general but have concerns about the use of fertilisers recovered from human excreta. For example, a large part of society understands the term "alternative toilets" to mean primitive latrines, which leads to doubts about aesthetic standards and toilet comfort (Del Morales et al., 2014).

For the general restructuring of urban water management towards a sustainable and ecological approach, it is inherently important to consider different levels of perspective. The challenge of closing the loop for a material such as phosphorus, potassium and nitrogen must therefore be met not only at the political, economic, and technical level. In particular, society and the public are the foundation for the success of such far-reaching restructuring processes. Creation and expansion of the overall social awareness and thus acceptance is decisive for this. The reframing of human excreta management as part of food and farming systems has potential to support long-term global food, soil, and nutrient security while also reducing the risk of compromising other priorities related to health and environmental issues (Harder et al., 2020).

Accordingly, knowledge and user acceptance are essential for a broad implementation of ROS in municipal sanitation systems. Citizens are important decision-makers in their role as tenants, home owners, and buyers of recycled products from human excreta (Pahl-Wostl et al., 2003).

\subsection{The perception of the role of excreta}

The transformation of research results and elite knowledge into education and information for the general public is of great importance for the social acceptance of such approaches. In modern society, the issues of human excreta and excretion itself are viewed primarily negatively or avoided altogether. Individuals want to be disassociated from the act of producing urine and faeces and view the substances as disgusting and worthless. The very wording of the visit to the toilet implies a distancing from the activity itself, such as going to the bathroom or restroom. In addition, terms referring to excreta and the associated body parts are used often as swear words or jokes. These psychological effects can lead to health impairments. For example, it can lead to inhibition of micturition in the presence of other people in public toilets or, in the worst case, not using the toilet, and can even affect the hydration of the body (Haslam, 2012; Kira, 1976; Lundblad and Hellstrom, 2005; Michels et al., 2019; Middlemist et al., 1976; Weinberg and Williams, 2005).

With regards to the psychological and social aspects of excretion per se, a fundamental change in the associations of quickest possible disposal and the consideration of human excreta as worthless, disgusting substances to the actual usability and value of the nutrient-rich substrates is crucial.

\subsection{Objectives and approach}

Our approach to solving the problem is to create and expand public attention and awareness. The project "Phosphorus Bank" (P-Bank), funded by the German Federal Foundation for the Environment, combines the advantages of material flow separation with the treatment of urine for the production of fertilisers. The aim of the project was to create an information platform that enables an interactive approach to the aforementioned topics for a wide range of target groups. The focus was on the transport of straightforward information and the communication of contexts. For a wide audience reach and a seamless integration of the new approaches into the daily life of the users, the object chosen was the toilet in public space. 


\section{DEVELOPING THE P-BANK}

For the design of the communication, we have considered and applied a variety of approaches from pedagogy and architecture. The key basis for all awareness-raising and information campaigns of new technologies and in particular of new sanitation systems is to ensure the functionality of the technical equipment. Most important for the communication of a topic that is regarded negatively or reluctantly addressed in society is architectural interior design. Transforming the toilet visit into a positively connotated activity and enabling pleasant associations, the design, and the resulting atmosphere are essential. In addition, a pleasant environment is crucial for the sense of well-being and thus conducive to learning processes. Based on studies like Fich et al. (2014), Krüger and Zannin (2004) and Vartanian et al. (2013), the top priority for the design of the communication platform was an aesthetic design of the rooms and pleasant acoustic, thermal, and lighting conditions.

The public space is not a defined place but is always formed by the individual values of those whom it comprises (Wildemeersch, 2012). For progress and a sustainable change of views, public space, social encounters, and civic pedagogy must be kept open and undecided (Ellsworth, 2005). The communication concept of the P-Bank is based on an open installation in the public space for a visitor selection that is as heterogeneous as possible.

The basic ideas for the information design are based on the combination of learning concepts such as experiential (Kolb, 1984), active (Krempl et al., 2016), and subject-oriented learning (Teichmann et al., 2019). To take into account the complexity of the learning styles, skills, and modes discussed in pedagogy (Biesta, 2006; Boyatzis and Kolb, 1991; Davidson, 1984; Kolb and Kolb, 2018; Ryan and Charman, 2014), different learning channels are used and all senses are addressed to make the transported information more memorable (Falk and Dierking, 1998). The focus is on very open non-verbal or short verbal information provided to make the most of the potentially very short time windows and to give the visitor control over the information and learning process.

The theory of reasoned action and planned behaviour includes several aspects that influence behaviour (Ajzen, 1991). In addition to social and moral values, factual knowledge plays a major role. However, many studies describe the connection between factual knowledge and behaviour with regards to environmental knowledge and ecological behaviour as low to non-existent. According to Kaiser et al. (1999), when the connections are stronger, knowledge about ecological behaviour (e.g. what and how it can be done) is of more interest than knowledge about the environment itself. According to Arshad et al. (2020), awareness and concern are also more important than the more difficult to change (Sayers, 2006) environmental attitude.

To initiate reflection and learning, normal flows of experience must be interrupted (Kolb and Kolb, 2018; Wildemeersch, 2012; Ellsworth, 2005). The goal of the P-BANK-concept is to create a transitional space, where the self-evident understanding of public toilets is inter- rupted and the user is invited or provoked to reconsider understandings and emotions. The P-BANK identifies alternatives without providing a ready-made opinion. The information on windows of opportunity in alternative system design is shown as an example in terms of urine recycling. Here the visitor receives a stimulus for independent information in discourse with others and, if desired, more in-depth research.

\section{THE P-BANK}

The P-BANK collaborative project combines the technical implementation of ROS with aesthetic design components. As an information platform combining a public toilet with nutrient recycling, the P-BANK creates opportunities for the identification with various individual interfaces concerning urine disposal and resource recovery. The main objective was to present and evaluate a newly designed toilet concept in public spaces to present ROS as an alternative to conventional sewage systems. Sensitising users to the shortage of the life-essential resource phosphorus $(P=$ "phosphorus") as well as the simultaneous misallocation of nutrients ( $\mathrm{P}=$ to "pee") and the resulting harmful impact on the environment is the stated purpose. Use in the public space enables the evaluation of the level of knowledge of the users as well as the supply of information to the users. The focus lies on the scarcity of resources and the solution approaches of ROS mentioned above. In addition, the user acceptance for alternative sanitation concepts amongst the population can be investigated.

\subsection{Transforming an everyday need into an interac- tive learning space}

The P-BANK is intended to create identification possibilities for the user with the help of an experiential space based on interfaces between urine disposal and potential resource recovery. The linked objective includes, on the one hand, the raising of awareness around the issues of phosphorus scarcity and sustainable use of vital resources such as plant nutrients (especially phosphorus, nitrogen and potassium) and water. The aim is not only to present the problems, but also to present solutions that work directly. The second sub-goal is therefore to demonstrate marketable sanitation product solutions that contribute to closing natural cycles. Communicating ways to recycle urine, faeces and grey water using existing products such as recycled fertiliser is also aimed at.

The technical equipment combined with a communication and service concept is the key element of the P-BANK. The transformation of the toilet as a "quiet little place" into a design object in the form of a donation bank for nutrients leads to an image change of public toilets.

The idea of conveying information with the communication concept of the P-BANK follows different principles. Essential is an aesthetically pleasing design that ensures a convenient learning atmosphere but does not interfere with the original purpose of the site visit. The toilet visit should be framed by a pleasant atmosphere to make the activity itself and the presented sanitary systems as attractive as possible. The interactive design of the concept is decisive 
for the possibility of identification with the presented problem as well as the solution approaches. With the direct link to the use of the public toilet, a specific cycle can be shown as an excerpt from the possibilities of novel sanitary systems. The resulting simplification of the context is an important point for the comprehensibility of the information and the sustainability of the information transfer.

By focusing on nutrient recycling from urine or yellow water, an excerpt from the transformation potential of wastewater disposal is conveyed in an exemplary manner (Figure 1).

\subsection{Raising the awareness of ROS as an alternative to conventional sewers}

Based on the communication and information concept of the P-BANK, the user interaction points with urine disposal and resource recovery are arranged logically by the order of the stations related to a visit to the toilet. The visitor is led through a guided tour, which starts with the arrival at the entrance to the stairs of the P-BANK. The signs on the stairs introduce visitors to the topic of $P$ scarcity (Figure 2 and Figure 3 ).

\subsubsection{Nutrient donation}

Once aware of the singularity of the P-BANK public toilet and the topic, the user enters the waiting room, where the doors to the actual toilet rooms are located. The two rooms, containing a waterless urinal (WU) and a urine diversion toilet (UDT), are marked as donor rooms (Figure 4).

In short, the P-BANK is intended as a platform for presenting diverse sanitary installations and ROS concepts. In the current configuration "save!" (Gründl, 2018), a new type of flush separation toilet, is implemented, in which the separation is performed with a so-called urine trap based on the principle of surface tension at the bowl edge. This sanitary installation is characterised by differences to conventional flush toilets that are invisible to the user, which is a relevant aspect for the well-being and thus the impact of the P-BANK communication concept. The functionality of the separation of the urine either in the WU or in the UDT is explained with the help of labels and graphic illustrations. In the donor rooms, the user is invited to donate urine (pee) and in consequence the phosphorus $(P)$ by signs on the wall or the floor (dependent on the type of sanitary installation). During the toilet visit, the phosphorus cycle is presented to the user graphically in a simplified form (Figure 5).

\subsubsection{Nutrient recycling from urine}

The guided tour continues at the next station - the washbasin. Here the user is introduced to the urine treatment units, which are located behind a transparent PET screen instead of a mirror above the basin (Figure 6). As with the sanitary facilities, the P-BANK will also serve as a modular presentation platform for the treatment processes.

\section{P) Bank}

Exhaustable Essential Ressources

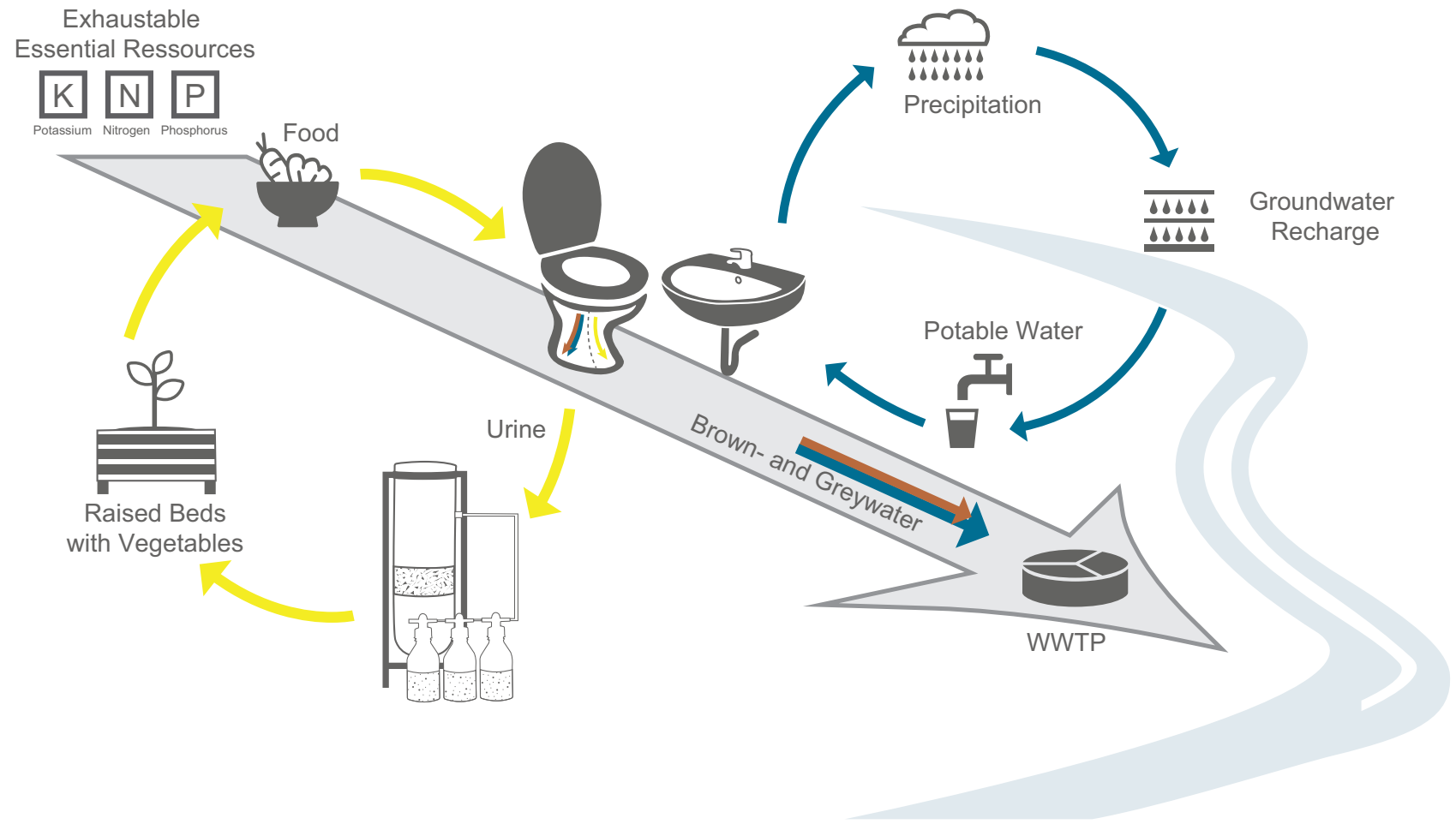

FIGURE 1: Decreased information content for a simplified knowledge transfer at the P-BANK. 


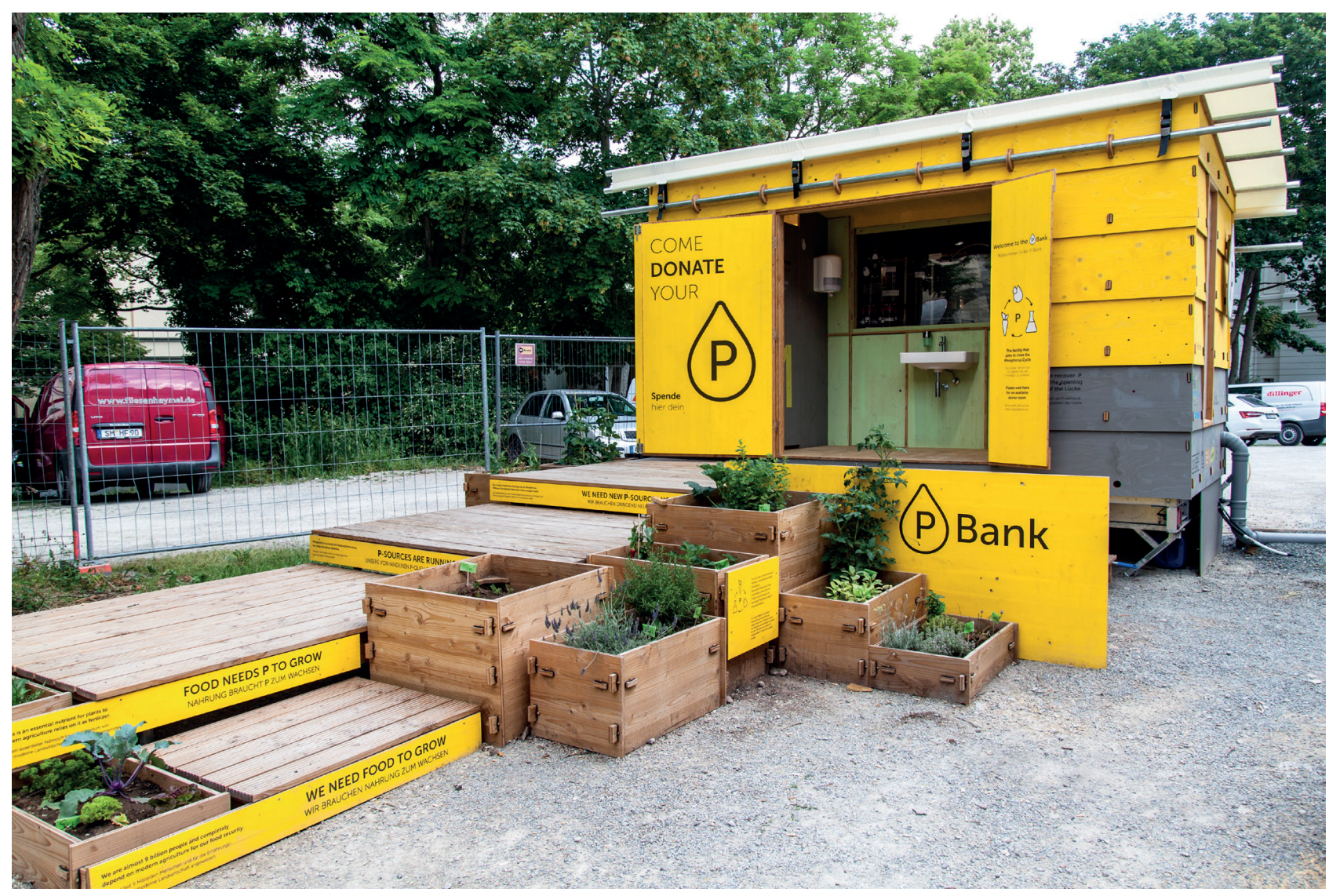

FIGURE 2: Exterior view of the P-BANK on the premises of the Bauhaus-Universität Weimar in 2019.

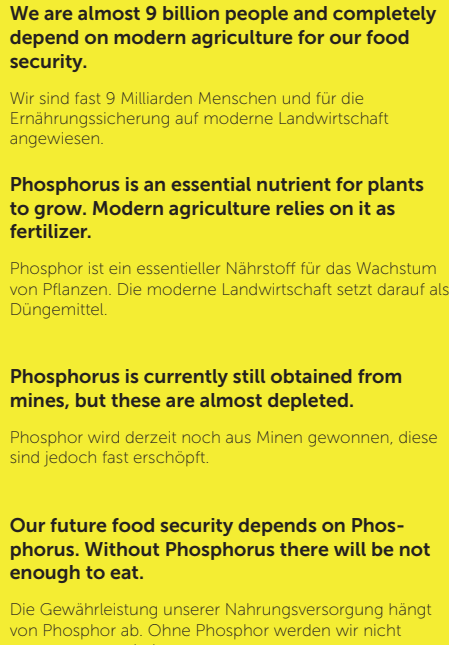

\section{WE NEED FOOD TO GROW WIR BRAUCHEN NAHRUNG ZUM WACHSEN}

\section{FOOD NEEDS P TO GROW}

NAHRUNG BRAUCHT P ZUM WACHSEN

\author{
P-SOURCES ARE RUNNING LOW \\ UNSERE VORHANDENEN P-QUELLEN SIND BALD AUFGEBRAUCHT
}

\author{
WE NEED NEW P-SOURCES NOW! \\ WIR BRAUCHEN DRINGEND NEUE P-QUELLEN!
}

FIGURE 3: Stair signs of the P-BANK telling the causal chain from $P$ use to $P$ recycling.

The selection of the methods has to be made straightforward to explain and to generate substances that can be used as fertilisers to enable the nutrient cycle to be closed. While installing the treatment processes, particular attention was paid to ensuring the best possible clarity and transparency. The production of the nutrient-containing end products was also to be illustrated. The order of the individual process steps is indicated by a numbered se- quence identification. In addition, for each sub-process, a simple short explanation, understandable for non-experts, is provided in close proximity to the processing.

In the current setup, the urine treatment consists of two recycling lines, which are operated independently of each other for demonstration purposes to indicate the large variety of possible treatment processes of ROS.

Line 1 (Figure 6, left-hand side) includes treatment us- 


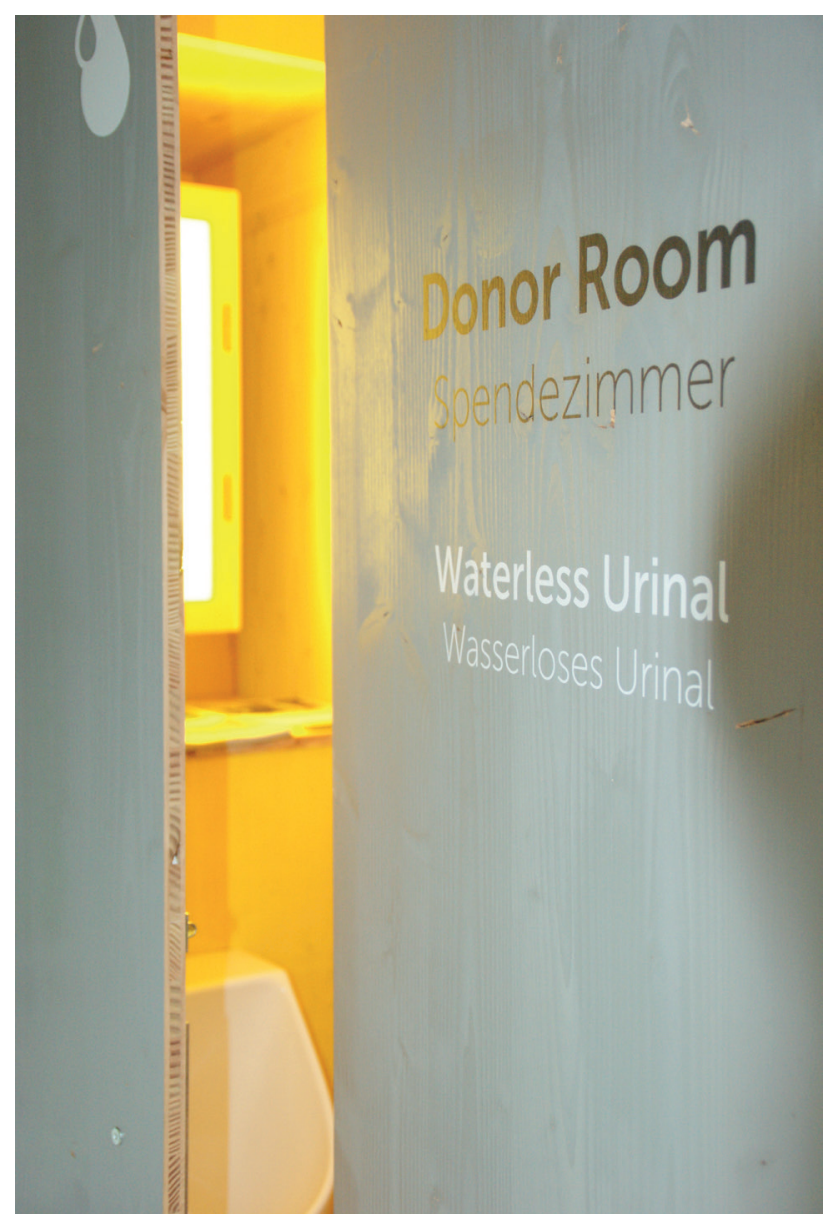

FIGURE 4: Donor room with waterless urinal. ing the biological and physical processes of urea hydrolysis followed by ammonia stripping with simultaneous precipitation on a carrier material and subsequent acidic gas scrubbing. The advantage of this combination of treatment steps is the simple structure and the visible introduction of air followed by the removal of ammonia from the urine and its washing in sulphuric acid. All components of the treatment process are transparent. For the gas stripping by air injection, a large bubble process was chosen to increase visibility. For the same reason, the indicator solution methyl orange was added to the gas scrubbing to indicate the consumption of the sulphuric acid and a change in the state and thus the composition of the solution. The resulting products are phosphorus salts on the carrier material and liquid ammonia sulphate.

Line 2 (Figure 6, right-hand side) based on the urine treatment unit in the blue diversion toilet of Eawag consists in the first step of the alkaline stabilisation using hydrated lime addition (Decrey and Kohn, 2017, Randall et al., 2016). This is followed by the drying of valuable substances by trickling the stabilised urine at a greatly reduced flow rate onto distribution plates with a low slope combined with simultaneous aeration of the plates (Antonini et al., 2012, Pahore et al., 2010, Udert et al., 2003, Udert et al., 2006). The exhaust air is cleaned by an activated carbon filter to avoid odour disturbance. Regarding the visibility of processes and products, the most important point of building this treatment line is the transparency of the evaporation reactor in the form of a display case with flow plates. This enables the presentation of the produced phosphorus salts on the plates.

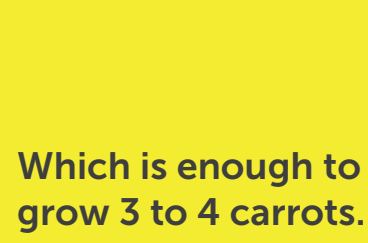

Was für das Wachstum von 3 bis 4 Möhren ausreicht.

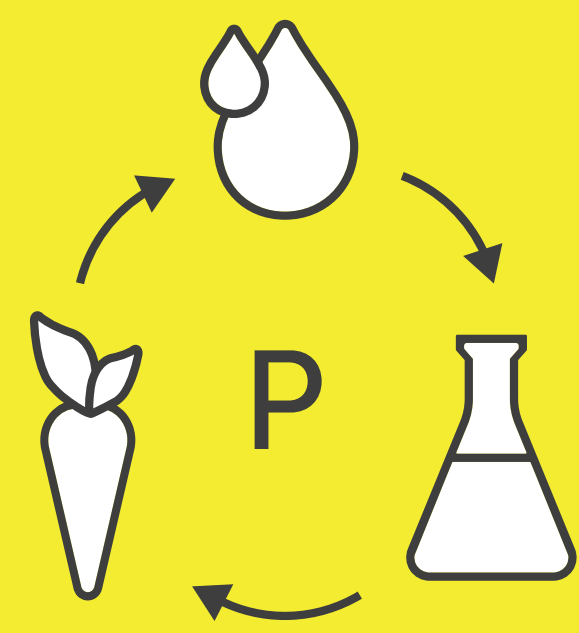

Right now, you are donating about 300 $\mathrm{ml}$ Pee to the P-Bank.

Gerade spendest du etwa $300 \mathrm{ml}$ Urin an die P-Bank.

This contains about
$200 \mathrm{mg}$ of Phosphorus.

Damit kann man 200 mg

Phosphor zurückgewinnen.

FIGURE 5: The Phosphorus cycle explained in relation to the P-BANK stations. 


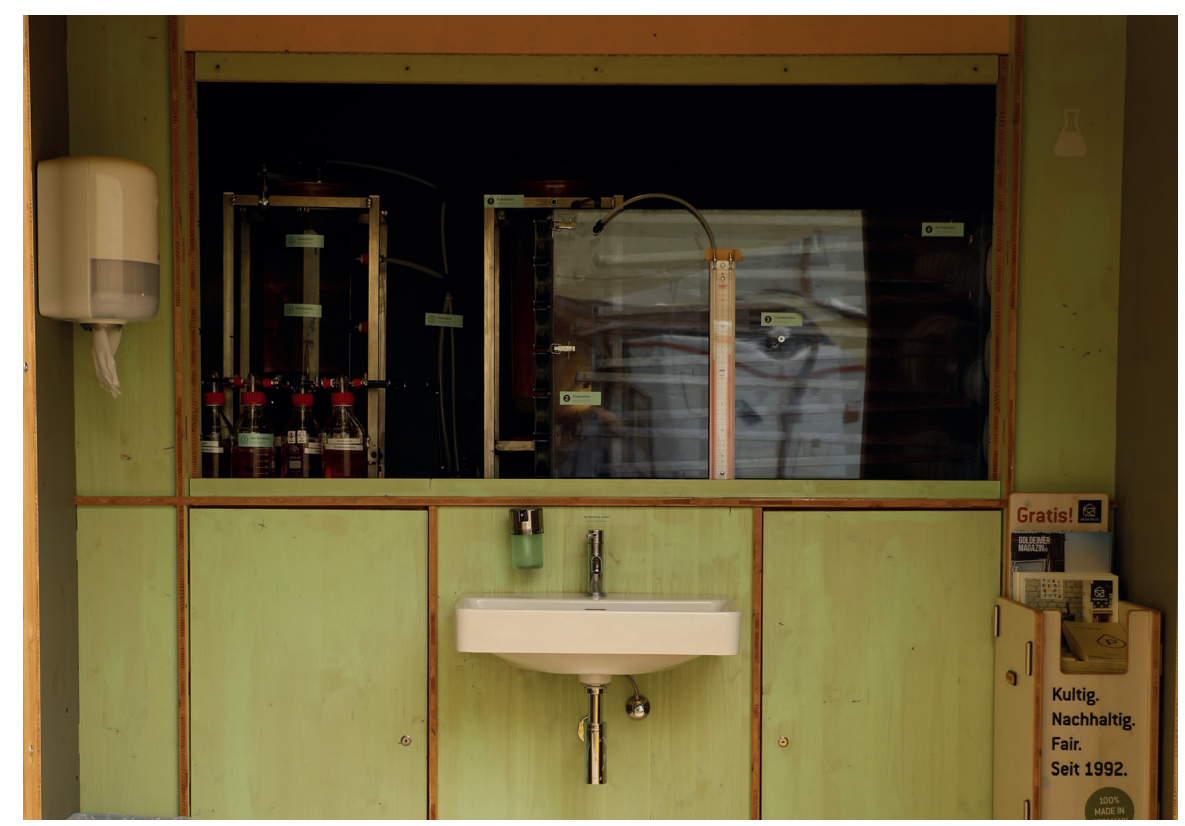

FIGURE 6: Urine treatment units inside the P-BANK.

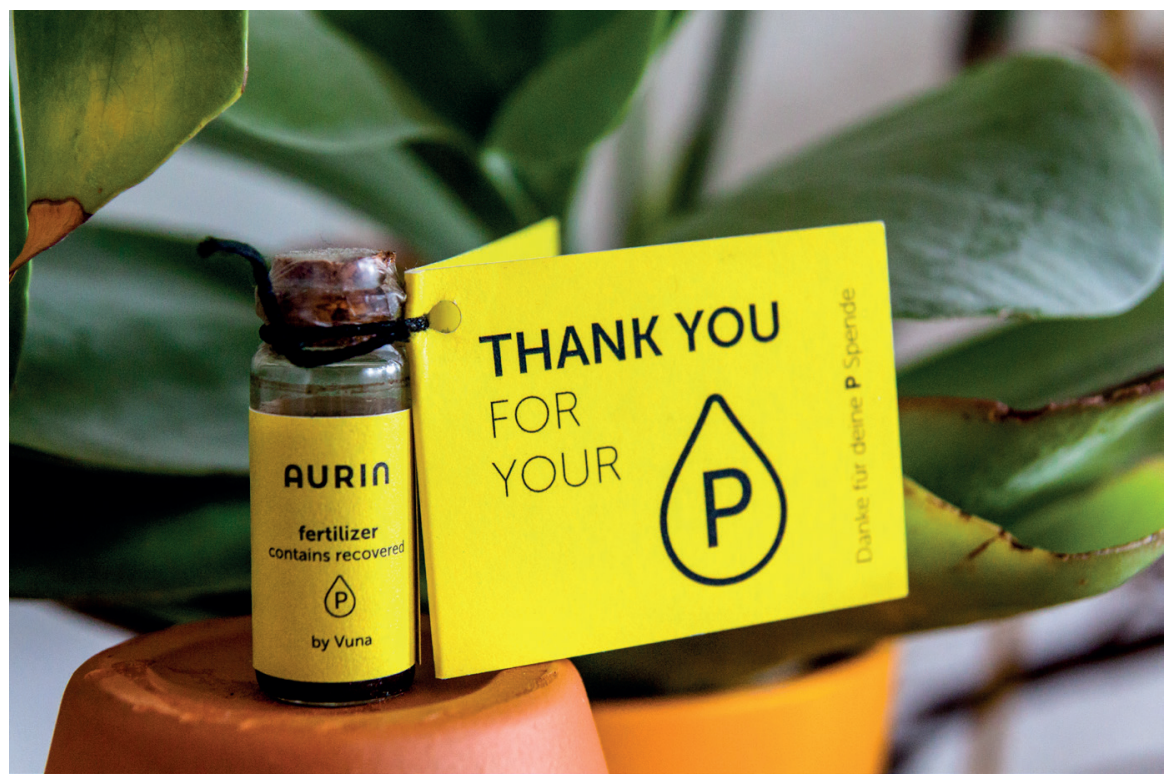

FIGURE 7: AURIN fertiliser as a thank you gift for the P donator.

\subsubsection{Nutrient reuse}

On leaving the P-BANK, the P-donor receives a thankyou gift in the form of a sample of AURIN, a urine-based liquid fertiliser from VUNA GmbH (Etter et al., 2015) designed for the P-BANK using the unique style (Figure 7). On the way out, the user's path is flanked by raised beds of herbs and vegetables that symbolise the final use of the generated fertiliser (see Figure 2). At this point, the phosphorus cycle is completed.

\section{EVALUATING THE P-BANK}

The first location of the P-BANK was the campus of the Bauhaus-Universität Weimar during the celebrations of the 100th anniversary of the Bauhaus. The facility was operated for four months close to the pop-up restaurant "Die Lücke", which was particularly suitable as a location because of the sustainability concept used and the raised beds for herb production. Based on sample counts on 7 unrelated days (Figure 8, left-hand side), the number of users of the whole P-Bank system during this first test period was approximately 4,700 (extrapolated on the basis of the median of the sample measurements). Of these, on average $70 \%$ used the UDT. The measured urine volume shows a slightly lower mean value for the UDT compared with the sum of both toilet types (Figure 8, right-hand side).

The evaluation of the P-Bank included in the first step 

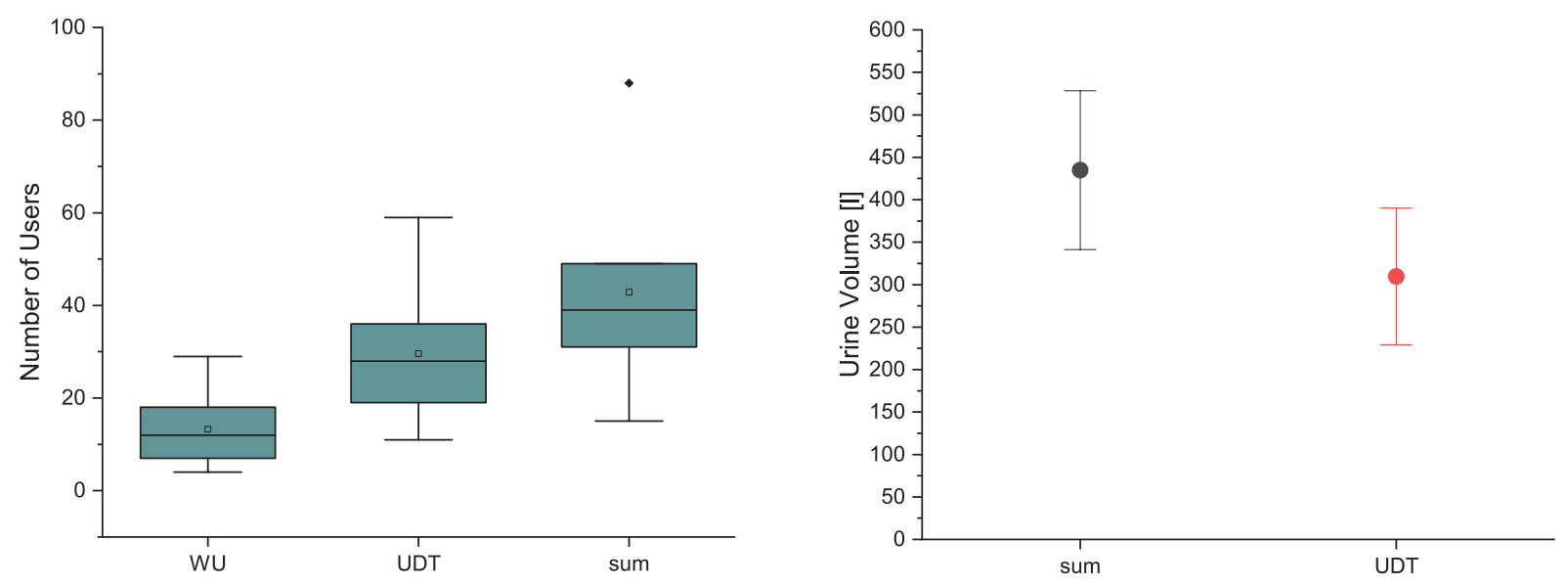

FIGURE 8: Number of visitors and urine volume per use during test period 1.

the examination of the functionality of the technologies used. In detail, the separation performance of the urine collection units was examined and compared with common volumes and substance concentrations in urine (Bauhaus-Institute for Infrastructure Solutions, 2016). To evaluate the functionality of the urine treatment units of the P-BANK, we analysed the characteristics of the solid products of both treatment lines.

The investigation of the effectiveness of the communication concept was based on a combination of quantitative and qualitative analyses. The advantages of combining both research methods lie in the extension and deepening of the results and conclusions by increasing openness and questioning the quantitative analysis (Harland and Holey, 2011; Mayring, 2001; Reja et al., 2003).

\subsection{Technical Evaluation}

\subsubsection{Degree of separation of the collection system}

During the first test phase, the urine was collected and analysed on a sample basis and compared with the guideline values according to Bauhaus-Institute for Infrastructure Solutions (2016). The results (Figure 9) show that the collected urine had lower concentrations for COD

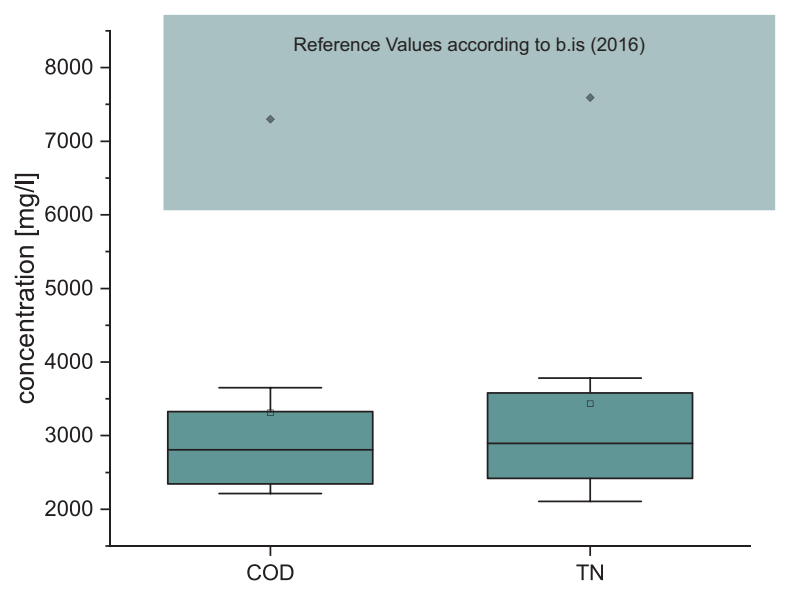

FIGURE 9: Boxplots of parameters of samples of the P-BANK users during test period 1. and total nitrogen (marked as outliers), while values for sulphate and potassium were within the expected range. The neighbouring pop-up restaurant was characterised by the fact that meals were not offered continuously during opening hours. It can therefore be assumed that beverages were consumed predominantly. As most toilet users were restaurant guests, it can be assumed that this may be a reason for the dilution.

\subsubsection{Analysis of the produced materials}

The analysis of all carrier materials showed little accumulation of phosphates, calcium, potassium, and magnesium, although the values are very low (Table 1). Additional crystalline substances were found inside the stripping unit that also consisted of the aforementioned elements. As the treatment units were built for demonstration issues without aiming for high efficiency, the low values are not surprising but still demonstrate the functionality.

\subsection{Reception of the P-BANK}

The interviewees were P-Bank users who were willing to participate in the survey by filling in the questionnaire themselves. The use of the P-Bank was voluntary and on their own initiative. This was ensured by its location in public space. The quantitative analysis $(n=55)$ consisted of a demographic survey of the respondents and the collection of five-point Likert-data on the effectiveness of the P-BANK. The investigation of the learning effects was evaluated using dichotomous questions in correlation with the personal previous knowledge as this knowledge is relevant particularly for the understanding of the communicated contents (Wilde, 2007). To extend the closed analysis, open questions were asked about subjective optimisation possibilities.

The individual environmental attitude varies depending on the topic. Furthermore, better predictions for specific environmental behaviour are based on the measurement of specific attitudes (Kaiser et al., 1999). For this reason, Likert-scaled questions such as the understanding of the function of resource-oriented sanitation systems, the environmental impact of such technologies, and the willingness to use them at home were used to investigate the 
TABLE 1: Analysis of the solid substances.

\begin{tabular}{|c|c|c|c|c|}
\hline \multirow{2}{*}{ Sampling point } & $\mathbf{K}$ & $\mathrm{Ca}$ & $\mathbf{P}$ & $\mathrm{Mg}$ \\
\hline & \multicolumn{4}{|c|}{$\mathrm{m}-\%$} \\
\hline Crystalline Substances (stripping unit) & 3,15 & 0,43 & 4,98 & 0,02 \\
\hline Carrier Material (stripping unit) & 3,01 & 0,37 & 2,16 & 0,021 \\
\hline Carrier Material (Evaporation unit) & 1,39 & 0,65 & 0,76 & 0,042 \\
\hline
\end{tabular}

specific attitude towards novel sanitation systems.

In order to estimate the reach in its entirety, we draw conclusions about the number of people reached on the basis of media-effective publications. This is based on publications on the Internet, social media posts as well as print media and television and radio reports.

\subsubsection{Demographic data and user experience}

The quantitative and qualitative data collection was performed during the time of operation in summer 2019 to obtain an overview of the perception of the P-BANK concept. Of the users who took part in the survey, 38\% were male, $58 \%$ female and $4 \%$ gave no information. $9 \%$ of respondents were under $25,42 \%$ were between 26 and 40 years old, $36 \%$ were between 41 and 65 years old, $13 \%$ were over 65 . In terms of employment status, the largest share of participants $(67 \%)$ were professionals. $2 \%$ of participants were school students, $15 \%$ retired and $7 \%$ said "other". Despite being located close to the university campus, only $9 \%$ were students.

The median and mode value of the Likert data on the convenience of the P-BANK was five. In detail, the visit to P-BANK was considered a very positive experience with very good hygiene and comfort. The clarity of the explained contents was evaluated with 4 out of 5 points in median and mode. The majority of respondents answered this question with 4 to 5 out of 5 points.

\subsubsection{Knowledge enhancement}

An interesting aspect of the survey is the symmetrical nature of the knowledge gained during the P-BANK visit in correlation with prior knowledge. Visitors with no previous knowledge of resource-oriented sanitation systems perceived the visit as a gain in knowledge; visitors with previous knowledge did not attest to this.

From the group of respondents who had heard about such sanitary systems in advance, the response to the question of whether such systems are environmentally friendly and the question of home use in the median and mode was 5 (I strongly agree). In the group of respondents with no prior knowledge, resource-oriented sanitation systems were also classified as environmentally friendly, and the question of private use was given a somewhat more cautious rating of 4 ( $\mathrm{l}$ agree) in the median and mode. The qualitative part of the survey revealed in many cases a desire for more in-depth information on the systems propagated but also for basic knowledge of the existing conventional approach. Also, there were many questions about why this system is not yet implemented on a larger scale.

\subsubsection{Response of press and public}

The response of the press and public was reflected in radio and television reports, newspaper articles and social media contributions. The radio and television reports were shown in regional and national programmes of the public-law institutions. The total of all audience ratings of the relevant TV and radio programmes amounted to around $2,178,000$ listeners and viewers. The primarily regional daily newspapers have a total daily circulation of 874,478 copies. Social media contributions were made by companies, public institutions and private individuals on the platforms Facebook, Instagram and Twitter. The total number of followers of all pages was 1,633,232, of which 5,798 interacted with the posts. In summary, in addition to the local P-Bank users, a potential audience of 4,685,710 can be assumed and the number of users who confirmed their knowledge of the content through active interaction can be determined at 5,798 .

\section{OUTLOOK}

There are some limitations associated with the results. Therefore, the examination must be regarded as a pilot study. The investigation of the degree of separation of urine in the collection units was conducted on a random basis and therefore represents the investigation period as an example. During the first study, the location of the P-BANK on the university campus was near an alternative pop-up restaurant, thus providing a special setting. The age structure and distribution of the professional status of the respondents is acceptable at best. The voluntary use of the P-Bank and participation of the respondents in the evaluation could limit the picture of the impact of the P-Bank. The assessment of the press and public response makes no claim to completeness. Therefore, the assumed values should only be regarded as estimates. In addition, use was linked predominantly to a visit to a restaurant, which influences the status of the installation in public space and the characterisation of the collected urine.

The first testing campaign showed that the concept of the P-BANK interactive platform, in general, is appropriate for information campaigns and awareness-raising for the users on topics such as nutrient scarcity and possibilities of resource recovery from urine collected separately. The adaptation of the treatment plant for demonstration purposes resulted in losses in the efficiency of the recycling processes. Nevertheless, the functionality was still provided and the visible production of nutrient containing substances was guaranteed.

The portable unit will serve as an information and evaluation platform for alternative sanitation systems at other 
locations in the future and will be further investigated to optimise communication concepts regarding the functionality and advantages of ROS. The P-BANK can also be hired for information campaigns featuring other treatment methods for separately collected faeces or urine.

\section{ACKNOWLEDGEMENTS}

This research was supported by the German Federal Environmental Foundation. We thank our colleagues from Werkhaus $\mathrm{GmbH}$, Goldeimer $\mathrm{gGmbH}$, Eawag and EOOS, who provided insight and expertise that greatly assisted the research. Also, we would like to thank Laufen Bathrooms for providing the urine diverting toilet "save!". We would like to especially thank Anniek Vetter and Sylvia Debit for creating the design concept of the P-BANK in interdisciplinary cooperation with engineers.

\section{REFERENCES}

Ajzen, I. (1991). The Theory of Planned Behavior. Organizational Behavior and Human Decision Processes 50, 179-211.

Antonini, S., Nguyen, P.T., Arnold, U., Eichert. T., Clemens, J. (2012). "Solar thermal evaporation of human urine for nitrogen and phosphorus recovery in Vietnam." Sci Total Environ 414: 592-599.

Arshad, H; Saleem, K; Shafi, S; Ahmad, T. and Kanwal, S. (2020). Environmental Awareness, Concern, Attitude and Behavior of University Students: A Comparison Across Academic Disciplines. Polish Journal of Environmental Studies 30 (1), 561-570. https://doi. org/10.15244/pjoes/122617.

Bauhaus-Institute for Infrastructure Solutions (b.is) (Hrsg.) (2016). New Alternative Sanitation Systems - NASS. Weimar: Weiterbildendes Studium Wasser und Umwelt, Bauhaus-Universität Weimar. ISBN: 978-3-95773-213-2

Biesta, G. (2006). Beyond learning. Democratic education for a human future. London/New York, Routledge/Taylor and Francis Group.

Blanken, M.; Verweij, C.; Mulder, K. (2019): „Why novel sanitary systems are hardly introduced?". In: Journal of Sustainable Development of Energy, Water and Environment Systems. 7 (1), S. 13-27, DOI: 10.13044/j.sdewes.d6.0214

Boyatzis, R.E. and Kolb, D.A. (1991). Assessing Individuality in Learning: the learning skills profile. Educational Psychology 11 (3-4), 279-295. https://doi.org/10.1080/0144341910110305.

Ciceri, D.; Manning, D.A.C. and Allanore, A. (2015). Historical and technical developments of potassium resources. The Science of the total environment 502, 590-601. https://doi.org/10.1016/j.scitotenv.2014.09.013.

Cordell, D.,Drangert, J.O. and White, S. (2009). The story of phosphorus: Global food security and food for thought. Global Environmental Change, 19(2), pp.292-305.

Council Directive 91/271/EEC on the approximation of the laws of the Member States concerning urban waste water treatment' (1991) Official Journal L135, p. 40.

Davidson, B. (1984). Styles in Teaching and Learning. Special Education: Forward Trends 11 (1), 19.

Decrey, L., and Kohn, T. (2017) Virus inactivation in stored human urine, sludge and animal manure under typical conditions of storage or mesophilic anaerobic digestion. Environmental Science: Water Research and Technology.

Del Morales, Margaret Carmen; Harris, Leila \& Öberg, Gunilla (2014). Citizenshit: The Right to Flush and the Urban Sanitation Imaginary. Environment and Planning A: Economy and Space 46 (12), 28162833. https://doi.org/10.1068/a130331p.

Ebert, I. (2013). Pharmaceuticals in the Environment - A first Compilation of German Monitoring Data. Technical report, EPA

EcoSanRes (2005). Closing the Loop on Phosphorus. , pp.1-2. Stockholm En-vironmental Institute (SEI). Schweden.

Ellsworth, E.A. (2005). Places of learning. Media, architecture, pedagogy. New York, RoutledgeFalmer.

Etter, B.; Gounden, T. and Udert, K. (2015). VUNA: Valorisation of Urine Nutrients - Final Project Report.
Falk, J.H.and Dierking, L.D. (1998). The museum experience. Washington, D.C. Whalesback Books.

Fich, L.B.; Jönsson, P.; Kirkegaard, P.H.; Wallergård, M.; Garde, A.H. and Hansen, ̊.. (2014). Can architectural design alter the physiological reaction to psychosocial stress? A virtual TSST experiment. Physiology and behavior 135, 91-97. https://doi.org/10.1016/j. physbeh.2014.05.034

Fust, A.P.; Jenert, T. and Winkler, C. (2018). Experiential or Self-Regulated Learning: A Critical Reflection of Entrepreneurial Learning Processes. Entrepreneurship Research Journal 8 (2). https://doi. org/10.1515/erj-2017-0098.

Gründl, H. (2018). Urine trap by: EOOS, EOOS Design GmbH, Vienna, Austria. Online available at http://urinetrap.com/src/assets/img/ UrineTrap.pdf

Harder, R.; Wielemaker, R.; Molander, S. and Öberg, G. (2020). Reframing human excreta management as part of food and farming systems. Water research 175, 115601. https://doi.org/10.1016/j. watres.2020.115601

Harland, N. and Holey, E. (2011). Including open-ended questions in quantitative questionnaires-theory and practice. International Journal of Therapy and Rehabilitation 18 (9), 482-486. https://doi. org/10.12968/ijtr.2011.18.9.482.

Haslam, N. (2012). Psychology in the bathroom. Basingstoke, Palgrave Macmillan.

Jones, D.L.; Cross, P.; Withers, P.J.A; DeLuca, T.H; Robinson, D.A.; Quilliam, R.S; Harris, I.M; Chadwick, D.R. and Edwards-Jones, G. (2013). REVIEW: Nutrient stripping: the global disparity between food security and soil nutrient stocks. Journal of Applied Ecology 50 (4), 851-862. https://doi.org/10.1111/1365-2664.12089.

Kaiser, F.G.; Wölfing, S. and Fuhrer, U. (1999). Environmental Attitude and Ecological Behaviour. Journal of Environmental Psychology $19,1-19$.

Kira, A. (1976). The Bathroom. 2. Aufl. New York, N.Y., Viking Pr.

Kolb, A. and Kolb, D. A. (2018). Eight important things to know about the experiential learning cycle. Australian Educational Leader 40 (3).

Kolb, D. (1984). Experiential learning: experience as the source of learning and development. New Jersey, Prentice-Hall Inc.

Kraus, F.; Zamzow, M.; Conzelmann, L.; Remy, C.; Kleyböcker, A.; Seis, W.; Miehe, U.; Hermann, L.; Hermann, R. and Kabbe, C.. (2019): Life cycle assessment comparison of P-recovery from the waste water stream with fertilizer production from rock phosphates, including consequential environmental damage and its prevention. Dessau.

Krempl, G; Lemaire, V; Lughofer, E. and Kottke, D. (2016). Active Learning: Applications, Foundations and Emerging Trends (Tutorial). In: G. Krempl/V. Lemaire/E. Lughofer et al. (Hg.). CEUR Workshop Proceedings. Graz.

Krüger, E.L. and Zannin, P.H.T. (2004). Acoustic, thermal and luminous comfort in classrooms. Building and Environment 39 (9), 10551063. https://doi.org/10.1016/j.buildenv.2004.01.030.

Larsen, T.A.; Udert, K.M.; Lienert, J. (2013): Source Separation and Decentralization for Wastewater Management. In: Water Intelligence Online. 12, DOI: 10.2166/9781780401072. - ISBN: 9781843393481

Lienert, J., Larsen, T.A. (2006) Considering user attitude in early development of environmentally friendly technology: A case study of NoMix toilets. Environmental Science and Technology 40(16): 4838-4844.

Lundblad, B. and Hellstrom, A.-L. (2005). Perceptions of school toilets as a cause for irregular toilet habits among schoolchildren aged 6 to 16 years. Journal of School Health 75 (4), 125-128. https://doi. org/10.1111/j.1746-1561.2005.00009.x.

Manning, D.A.C. (2018). Innovation in Resourcing Geological Materials as Crop Nutrients. Natural Resources Research 27 (2), 217-227. https://doi.org/10.1007/s11053-017-9347-2.

Manning, D.A.C. (2015). How will minerals feed the world in 2050? Proceedings of the Geologists' Association 126 (1), 14-17. https:// doi.org/10.1016/j.pgeola.2014.12.005.

Mayring, P. (2001). Combination and Integration of Qualitative and Quantitative Analysis. Forum: Qualitative Social Research 2 (1).

Michels, N.; van den Bussche, K.; Vande Walle, J. and de Henauw, S. (2019). School Policy on Drinking and Toilets: Weaknesses and Relation With Children's Hydration Status. Journal of nutrition education and behavior 51 (1), 32-40. https://doi.org/10.1016/j. jneb.2018.07.001. 
Middlemist, R.D.; Knowles, E.S. and Matter, C.F. (1976). Personal space invasions in the lavatory: Suggestive evidence for arousal. Journal of Personality and Social Psychology 33 (5), 541-546. https://doi. org/10.1037//0022-3514.33.5.541.

Pahl-Wostl, C., Schönborn, A., Willi, N., Muncke, J., Larsen, T.A. (2003). Investigating consumer attitudes towards the new technology of urine separation. Water Sci. Technol. 48, 57-65. https://doi. org/10.2166/wst.2003.0015

Pahore, M.M., Ryusei, I., Funamizu, N. (2010). Rational design of an onsite volume reduction system for source-separated urine. Environ Technol 31(4): 399-408.

Randall, D.G.; Krähenbühl, M.; Köpping, I.; Larsen, T.A.; Udert, K.M. (2016). A novel approach for stabilizing fresh urine by calcium hydroxide addition, Water Research, 95, 361-369,

Razon, Luis F. (2018). Reactive nitrogen: A perspective on its global impact and prospects for its sustainable production. Sustainable Production and Consumption 15, 35-48. https://doi.org/10.1016/j. spc.2018.04.003.

Reja, U; Manfreda, K.L; Hlebec, V. and Vehovar, V. (2003). Open-ended vs. close-ended questions in web questionnaires. Developments in applied statistics 19 (1), 159-177.

Rockström, J.,Steffen, W.,Noone, K.,Persson, Å.,Chapin, F.S.,Lambin, E.F.Lenton, T.M.,Scheffer, M.,Folke, C.,Schellnhuber, H.J.,Nykvist, B.,Wit, C.A. De,Hughes, T.,Leeuw, S. Van Der,Rodhe, H.,Sörlin, S.,Snyder, P.K.,Costanza, R.,Svedin, U.,Falkenmark, M.,Karlberg, L.,Corell, R.W.,Fa-Bry, V.J.,Hansen, J.,Walker, B.,Liverman, D.,Richardson, K.,Crutzen, P. and Foley, J.A. (2009). A safe operating space for humanity. Nature, 461(September), pp.472-475

Ryan, M. and Charman, K. (2014). Learning and teaching in public spaces (LTPS). Final report of the project titled Collaborative exchanges with museums to engage humanities and education students in experiential learning and citizenship. Department of Education. Sydney.

Sayers, R. (2006). Principles of awareness-raising for Information Literacy. A case study. Bangkok, Thailand, UNESCO.

Schaum, C. (2018). Phosphorus: Polluter and Resource of the Future: Motivations, Technologies and Assessment of the Elimination and Recovery of Phosphorus from Wastewater. Integrated Environmental Technology Series. London: IWA Publishing.
Schramm, E.; Kerber, H.; Trapp, J.H.; Zimmermann, M. and Winker, M. (2018): "Novel urban water systems in Germany: governance structures to encourage transformation". In: Urban Water Journal. Taylor and Francis 15 (6), S. 534-543, DOI: 10.1080/1573062X.2017.1293694.

Shouler, M., Griggs, J. and Hall, J. (1998). Water conservation. British Research Establishment (BRE)

Steen, I. (1998). Phosphorus availability in the 21st Century: management of a non- renewable re-source. Phosphorus and Potassium 217 , pp. 25-31.

Teichmann, M.; Ullrich, A. and Gronau, N. (2019). Subject-oriented learning - A new perspective for vocational training in learning factories. Procedia Manufacturing 31, 72-78. https://doi.org/10.1016/j. promfg.2019.03.012

Udert, K.M.; Larsen, T.A.; Biebow, M.; Gujer, W. (2003) Urea hydrolysis and precipitation dynamics in a urine-collecting system, Water Research, 37(11), 2571-2582, doi:10.1016/S0043-1354(03)00065-4, Institutional Repository

Udert, K.M.; Larsen, T.A.; Gujer, W. (2006): Fate of major compounds in source-separated urine. In: Water, Science and Technology 54 (1112), S. 413-420. DOI: $10.2166 /$ wst.2006.921

Vartanian, O.; Navarrete, G.; Chatterjee, A.; Fich, L.B.; Leder, H.; Modroño, C.; Nadal, M.; Rostrup, N. and Skov, M. (2013). Impact of contour on aesthetic judgments and approach-avoidance decisions in architecture. Proceedings of the National Academy of Sciences of the United States of America 110 Suppl 2, 10446-10453. https:// doi.org/10.1073/pnas.1301227110.

Weinberg, M. S. and Williams, C. J. (2005). Fecal Matters: Habitus, Embodiments, and Deviance. Social Problems 52 (3), 315-336. Online available at http://socpro.oxfordjournals.org.

Wilde, M. (2007). Das Contextual Model of Learning - ein Theorierahmen zur Erfassung von Lernprozessen in Museen. In: Dirk Krüger/Helmut Vogt (Hg.). Theorien in der biologiedidaktischen Forschung. Berlin, Heidelberg, Springer Berlin Heidelberg, 165175.

Wildemeersch, D. (2012). Imagining pedagogy in public space: visions of cultural policies and practices in a city in transformation. International Journal of Lifelong Education 31 (1), 77-95. https://doi.or $\mathrm{g} / 10.1080 / 02601370.2011 .63638$ 